\title{
Impact Factors on Social TV Research in Real Elderly Persons' Households
}

\author{
Claudia Müller ${ }^{1}$, Johanna Schnittert ${ }^{2}$, Magdalena Walczuch², Malek Alaoui ${ }^{3}$, \\ Myriam Lewkowicz ${ }^{3}$, Lin $\mathrm{Wan}^{2}$, Volker Wulf ${ }^{2}$ \\ Information Systems, IT for the Ageing Society, University of Siegen, Germany ${ }^{1}$ \\ Information Systems \& New Media, University of Siegen, Germany ${ }^{2}$ \\ ICD, HETIC, Tech-CICO, Troyes University of Technology, France ${ }^{3}$
}

\begin{abstract}
There has been a lot of interactive/social TV research and a lot of projects argued before the tablet boom with the elderly person's familiarity of TVs over PCs. However, not much research looked at appropriation processes of social/iTV prototypes from a holistic point of view, i.e. in the context of Living Lab research which includes reflection about socio-cultural issues in the realm of the TV watching practice. In this paper, we present research results and methodological reflections focussing on the interweaving of socio-cultural issues to social/iTV research with challenges in setting up and pursuing a long-term practice-based Living Lab project. We would like to sensitize other social/iTV researchers who do Living Lab research in real households of elderly people for possible obstacles and opportunities and open up a discussion on these practice-based social/iTV research issues.
\end{abstract}

\section{Introduction}

A great share of research initiatives are concerned about elderly peoples' cognitive and physical health. More and more research has found a strong relationship between health and social isolation. Recent studies indicate that the risk of mortality of elderly people is related to the lack of their social relationships (Holt-Lunstad et al. 2010). Aging people want to live in their homes as long as possible. If elderly people have fragile social networks there is a $60 \%$ higher chance that they experience social decline (Seeman 1996). Therefore a social TV system for elderly people that aims to improve their well-being and self-esteem has been developed. Where social TV describes a technology that "allows remote viewers to socially interact with each other via the television set, smart phones, tablets or the PC, where viewers might be separated in time and/or in space" (Cesar \& Geerts, 2011). In this paper we want to first describe our research context and issues. Then we will discuss the methodological chal- 
lenges while doing social TV living lab research. Next we present our observations related to the usage of social TV systems by elderly people.

\section{Related Research}

In the field of interactive and social TV research for elderly users there are a lot of findings directed to functional aspects. Palviainen et al. (2013) show that certain shows are better suitable for chat communication than others. Other researchers discuss the question if and how iTV would be interesting for the elderly on a more general level. Harboe et al. (2007) and Melenhorst et al. (2006) emphasize that an interactive and social TV application must add value to the experience of watching TV,e.g. in form of the feeling of being remotely togehter. Other researchers report on barriers of older users towards social network services: Norval $(2014,2)$ reports that older adults often find intentional self-presentation as not socially acceptable: "[...]barriers exist, such as a fear of committing social blunders, a lack of confidence, a lack of skill", and thus points out that it is an important task to reveal older adults' barriers concerning social network services to enhance seniors' online social communication.

Robertson et al. (2012) reflect trade-offs between efforts for learning the new technology versus the value gained from the viewpoint of the targeted users. To better understand these value trade-offs and the potential positioning of social/ iTV services in the elderly persons' every-day lives, Ducheneaut et al. (2008) claim to position more studies in the participants' homes and living environments. Living Lab methodology is such a research approach to bridge research and the live worlds of the target groups. However, there are many challenges when targeting elderly and not tech savvy persons for whom the technological ideas are far away from their every-day lives, such as in the area of social/interactive TV (Müller et al. 2015). Our research shows that for this special technical infrastructure research set-up issues are deeply linked with the elderlies' attitudes and practices around watching TV. That's why in the following we would like to report on a. methodological challenges for setting-up a Living Lab project and how these are linked to b. habits and attitudes of elderly persons around TV practices.

We start by describing problems during the installation phase and continue by investigating the distinct motivations of our participants in the research project. Due to the findings that reveal a lack of motivation, we present some reflections and ideas for a "motivation boost". Furthermore, we will depict empirical findings from our French and German samples. First we will describe our results concerning the elderlies' attitudes towards iTV and aspects which influence the uptake and use of such technologies. Our observations involve the use of second screen devices, social aspects, preferences for asynchronous communication and TV watching routines. 


\section{Description of the System and the Research Sample}

The Social TV system provides functionalities derived from former user studies (s. fig. 1). The selection of the functions has been reported elsewhere (Alaoui \& Lewkowicz, 2014). A.) A "friends list" which indicates which program and channel people from the own network are watching in order to promote social awareness. B.) With the "Stay in touch" module, the user is able to search for new "friends" and add them to the friends list and to exchange private messages. C.) "Channel Chat", where the users are able to chat about what they saw, are seeing or about other issues. In addition, to this synchronous communication, users also have the option to write asynchronous, private messages to friends. D.) Public discussions on topics of interest are possible in the "Clubs". Here the users can create discussion topics and communicate about it with others. E.) Another feature is the possibility to organise TV recommendations for friends. F.) Another mechanism to generate awareness is the so-called "Wall". The Wall is a list of recent activities of "friends" that appears on the screen when the Social TV application is started. As an additional user interface a tablet application is used to interact with the TV and for other inputs as the standard remote control is considered to be inappropriate for text input (Müller et al., 2012).

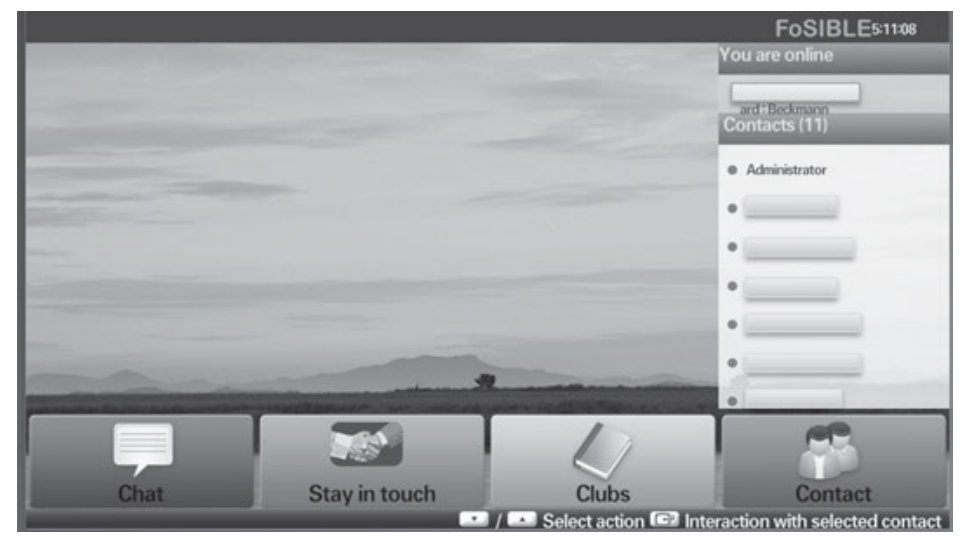

Figure 1: Social TV System: Start View

In France five people aged between 67 and 92 years participated in the evaluation phase that lasted six months. These participants were two men and three women, four of them widowers and one was single. The evaluation at home started with the administration of a pre-assessment questionnaire to the participants for an overview of their actual use of technologies. Then, we organized single demonstration sessions where we provided them with tools to support the uptake of the application and data collection (paper-based user guide and media dairy, and recorder to register vocal feedbacks). The first phase of the evaluation at participants' homes aimed to test the usability of the application during individual sessions. In Germany five households participated in the living lab evaluation. Over the course of six months they tested the social TV system in their houses. The households were being accessed via a local seniors' association, which, amongst others, runs 
a computer club to provide help to seniors with their ICT devices. In all of the participating households couples were living together, except one man was single. Out of nine participants there were six male and five female, aged between 64 and 82 years. Some of them had a closer relationship to each other, because of their joint board work at a local computer club. In the German sample the participants were provided with the same documentation tools as in France. All of the households had internet access, but in some cases further equipment and activities were necessary to install the additional equipment. Hence we had to visit the households at least twice and sometimes thrice to get the test running.

To support the appropriation of the Social TV system, we organised several workshops in the computer club for the participants - one in the beginning, to present the system to our users, two in between and one in the end to discuss the overall experiences with the system. For data gathering, we conducted qualitative interviews at the participants' houses every 3-4 weeks. Additionally, to better understand the elderly persons' general motivations and interests in using ICT (mainly notebooks and smartphones) bi-weekly visits to the computer club sessions have been accomplished. In these sessions, most of the household participants also participated, so that informal chats about their appropriation processes around the TV system could be led. In the computer club we positioned one Social TV system in order to gain further opinions from elderly people who did not participate in the project and also to discuss certain features with our participants. The activities in the computer club were an opportunity to foster chats and learning aids to the participants, but also a way to keep in touch and build trust. In both countries, the data collection consisted of the content generated by the participants inside the TV system, interviews and workshops. In addition, auto-ethnographic tools were used in form of a media diary and a self-reporting tool as a tablet app. Audio records of the interviews and workshops were taken and transcribed. Transcripts and other written data then was analysed on the basis of the precepts of qualitative data analysis. We held several analysis workshops (collocated and via skype) in the French-German team.

\section{$4 \quad$ Empirical Results}

\subsection{Methodological Challenges: Access and Motivations}

Technical inconveniences hinder Living Lab set-up: It was not only a great challenge to motivate the elderly to use the technology, but we also faced major problems when trying to get access to the elderly's homes to install the TV system. All participants had internet access, but since the TV system required a connection via an Ethernet cable and two households were only able to provide a wireless internet connection, we had to buy additional equipment and visit the participants' homes more often to ensure a proper installation of the system. Additionally, with the Samsung Smart TV module at the time, applications that run parallel to the TV program required specific TV reception modes. Some households had a satellite TV receiver, which was not supported by the system. Again we had to buy new equipment. In this case we bought TV antennas, but they were only able to receive public TV channels. As a result of these installation problems, it was not only that 
the households did not want us to install the TV system in their living rooms, but also that we were not able to fully replace their TV systems with our Smart TV. As they feared that the TV system could make problems with their known and well-organized channels, most of them made us set up the TV system in another room, e.g. the "home office".

Motivation to learn something new: The participants expected to learn about modern media. It was also important for some to learn how to use the technology of tomorrow now and not only when they need it: "It has to be learned at some point. We cannot start with this when we are out of shape. But we need to learn it now, as long as we haven't lost our mind." Some were interested in other media, such as to learn how to use a mobile phone.

Motivation to help or to do a favour: In addition to the motivation to learn something there was a strong tendency for the elderly participants towards the feeling that they wanted to help us and do us a favour: "We thought, okay, we will do this for two months straight and then we hopefully learned something and also helped the project" (female, 75).

Another general interest of the participants was to gain insights of the universities' research approach and structures.

iTV testing perceived as hard work: During the evaluation phase we looked at the participants' attitudes towards their regular usage of the system as Living Lab participants. Using the social TV system as part of the research project was perceived as work. This can be read in two ways. On the one hand, work is not fun and it's no leisure time for the participants. On the other hand, as a conscientious citizen, the work "just has to be done 2 or as one participant put it: "You have to plan time for when you use this device. This is why it reminded me of learning Latin vocabulary." Moreover conscientiousness, norms and values of the generation remind of a business relationship. The participants saw themselves as coresearchers who need to contribute: "We need to deliver first". The fact that they asked the university team for permission to "go on for vacation" leads to the conclusion that they perceive the participation in the project as work. Like in a business relationship they talked about "win-win situations" for both of us.

Furthermore the participants were strongly orientated to see the added value for themselves, but because of many usability problems and the unknown usage context they didn't really see added value in the system: "I do everything that is useful, has a value for me or that is fun". Even though they didn't see the added value, they tolerated the evaluation phase until the end.

The system is not as near to every-day life as other communication media: Some participants were informed about other Living Lab projects from our university, for example a project about fitness exercises or navigation support via smartphone. For some participants these applications were closer to their everyday practice than our project with our technical system. During workshops we all thought about how to arrange joint usage situations. These are covered in the following section. 


\subsection{A „Motivation Boost“ in the German Sample}

The effect of our methods to motivate the participants, such as visiting them, interviewing them and organising workshops decreased after the initial appropriation phase. To motivate the users to use the system more often collaboratively, the researchers then organized common "TV watching dates" with the participants for several evenings. The participants favoured different TV shows, but we were able to find at least a local news show in the early evenings which all were interested in. During this TV watching sessions the chat function of the system was then tested collaboratively by all households and the researchers. After the watching sessions, chats have been accomplished to understand the participants' feelings and attitudes during the sessions.

Another additional activity to foster the households' interactions with the system was the creation of a "virtual advent calendar" which contained activity prompts for each day in December (fig. 2). The "advent calendar" was devoted to foster daily interactions in the "club" section of the system. Below, the example shows the activity of Dec. 6th, a Christmas question: "What is the meaning of the word "advent"? Answers: a) Beginning of the winter time, b) Preparation, c) end of the year, or d) Arrival". One participants answer was: "It is a Latin word and d) is the correct answer. I always had good marks in religious education at school." Our participants even stated that they need special motivation from us in order to use the technology more often. "Without guidance, without someone who asks us to participate at certain times, I think it will not work for us." With the advent calendar we gave them the needed guidance and asked them to participate daily. They liked the advent calendar, because it reminded them of their childhood. During December, interaction with the system thus was quite high.
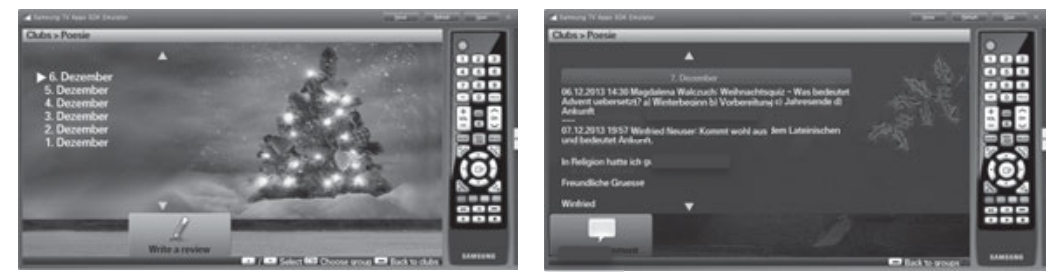

Figure 2. Advent calendar: start page \& quiz question

\section{3 "One Activity after the Other": No Multitasking Desired}

Despite the use of tablet devices as a remote control and a text input device, the elderly did not make use of the second screen while watching TV. Some used their tablets for watching movies, but they emphasized that they do so separately from watching TV: "No, I do not have the TV switched on when I am using the tablet. I am then watching the movie on the tablet. [...] I do not surf the web while I am watching TV."

The elderly were interested in looking up information about a show on the internet, e.g. they visit websites suggested during TV shows, but they always did it when the show was finished. In order to remember the internet address they often wrote it down on a paper note. 
Thus, they preferred to do "one thing after the other". A participant explained, this was because he is a man and therefore cannot multitask, while others say that is because they were always doing things in a sequential manner, for example during their work life or in the everyday life. It is a way of performing tasks and activities they learned when being younger which today helped them to organize their every-day lives.

\subsection{Communication: Synchronous vs. Asynchronous}

The elderly users preferred asynchronous, text based communication to synchronous forms. When using synchronous communication tools like chat there were several factors which hindered our users. Most of them became apparent after our joint TV watching session, when we chatted with our users during a news show. Further restrains became obvious in the discussion afterwards. Our first observation after the chat session was that the type of show we chose (news show) was not very suitable for a chat communication. On the one hand it provided many interesting topics one could discuss, but on the other hand it was difficult to follow the news and write chat messages simultaneously. Especially because the participants tended to write long, elaborate text messages. But we chose this local news show, because it was the only program which all participants were watching at the same time on the same channel. Furthermore the participants stated that they would only watch "educational" TV and no trash shows, which we had to acknowledge. Pointing at the "educational" programme they would only watch was - from the standpoint of presenting themselves - linked to their wish to write carefully and properly: "The way you write expresses a lot about yourself to others. That's why I always check carefully" (female, 75).

Plester et al. (2008) reveal that $90 \%$ of school children, including older teenagers and young adults, own phones and that $96 \%$ of them use text messaging. He even states that for them texting has a higher popularity than talking. While younger people are used to writing text messages, our users did not understand such communication habits, which is illustrated by a participant's astounded reaction, after we told him that for younger people it is common practice to chat while watching TV: "But then he can only write one or two sentences!" Our users did not distinguish between using a synchronous and an asynchronous communication channel. In both cases they wanted to write long, elaborate text messages. The remark of one woman about written communication shows her standard: "When I want to talk to someone, the telephone is much easier than formulating my thoughts into a decent, comprehensive German".

Another factor which influenced the use of synchronous communication has to do with social issues, such as social norms and expectations. The woman, who preferred speaking to a person on the telephone over writing a message, later on, came to the conclusion that writing someone a message is indeed not that bad. Her reasoning is that, when calling someone on the phone one could never know whether the other person is ready to answer the phone at this particular moment. Other participants also stated their concerns about the possibility to disturb or annoy the other person when they send him/her a chat message at the wrong moment. For example when watching soccer: "when I write the goal was good, at the same moment I am disrupting you. When you answer then you might not see the next goal". 
Also, when sending someone a chat message, one would at the same time send an obligation to reply to the other person. Some participants also perceived it as an obligation for oneself to write the other person a chat message when both of them were online at the same time. All in all the chat was perceived as "repressive and disruptive" and when using it the participants were constantly aware of how they might be perceived by others.

One participant who refused using the chat function explained that he has "never had the need to talk to a friend while watching a TV show". In his opinion it is "something for young people" with specific communication patterns and for older adults "not in demand". In the discussion after our chat session the participants made very clear that they did not want to chat during a TV show: "If at all, it might be a possibility to talk to someone after the show."

During visits at the computer club in Germany, we also made the experience that most of the elderly participants never use chat functionalities. Although many of them were passionate about using skype, they only used the voice- and video communication and never the chat.

Nevertheless the participants expressed their satisfaction about the Social TV services that were proposed; in particular, they perceived the written asynchronous communication functions (sending a message, participating in a club) as more useful and practical than the synchronous communication functions (chatting with some "buddies" when watching the same TV show). These results confirm Kanayama's (2003) study of an online community for Japanese older adults with a focus on self-disclosure and the exchange of social support (Kanayama 2003). She states that text-based online communication for older adults, much like writing letters, enhances rather than limits their ability to interact on a personal and emotional level. She also suggested that elderly people perceive the asynchronous nature of online communities and the possibility to edit messages before sending them as beneficial.

Participants stated that they greatly appreciated the asynchronous communication services (private messages and clubs). They justified this by the fact that they have more time to reflect on the content of the message before sending it, as summarised by one participant from the French sample: "Less immediate but it is easier to think about its message". In the French sample, the Club functionality was being used by the persons to participate in collective activities, by posting and sharing around their centre of interests. In the German sample people only used the Club functionalities for testing purposes at the beginning and during the advent calendar activity which was guided by the researchers. The different usage patterns in France and Germany are strongly linked to the difference in the sample of the living situation. The French, single living people took the Club functionalities as a window to get in touch with other single persons as an interesting option to overcome loneliness and boredom. The German sample, consisting of mainly couples and still active people did not see a lot of sense in this kind of communication as it was too loosely-coupled to other people.

\subsection{TV Watching Practices and Routines}

In Germany the users showed particular practices when watching TV. E.g., their everyday routines influenced their usage of the system. Since they had many leisure activities they told us to have no time for TV during daytime. They were constantly busy visiting their relatives 
or having visitors themselves, engaging in their hobbies, like gardening, cooking, computer club, or traveling. When they were watching TV they only did so in the evening: "we turn on the TV at seven p.m.". Their established daily routines did not include watching TV: "We meet in the living room. In the afternoon and evening everyone is in their room and [...] then we eat dinner together and watch the news afterwards. Then everyone continues doing his/her thing or we stay [in front of the TV]."

The usage of the social system turned out to be a strong intervention into the participants' everyday lives. The participants separated the usage of our system from their TV watching practice. One participant comments on her perception of using the social TV system as part of her TV watching routine: "when you count the time you spend in front of the TV as test phase, then it is an intervention [into my everyday life]. I mean, until now we did it under the motto: now we want to concentrate on [the study]... and when we are ready we can go upstairs and enjoy the evening".

We made the observation that it was difficult to talk about the individual TV watching practices due to social issues, such as norms and ways people wanted to be perceived by others. In the perception of most of the participants, different TV contents were linked to the expression and (self-) perception of educational levels.

\section{Discussion \& Conclusion}

When developing social TV applications for elderly users one has to consider that the TV watching practice and everyday routines of elderly people differ from those of younger target groups. This difference is most striking when it comes to the use of second screen devices which was not used by our elderly users, who preferred doing tasks in a sequential manner. Also synchronous communication tools like chat are not willingly used by the elderly. A social TV application can only be successful when it is able to add value to the experience of watching TV (Harboe et. al. 2007). There are also several social issues which affect the use of the social TV systems. The elderly's constant awareness of what the other participants might think of them or how their communication efforts might impact the other person influenced their usage. These findings have implications not only on the design of social TV applications, but also on the methodological approach when doing social TV research with older application partners.

Apart from functional recommendations, such as favouring asynchronous to synchronous communication options and to provide control mechanisms that are simple and intuitive, our results show significant hints to engage more into the design space of social/interactive TV solutions for the elderly. How can we better bridge the designers'/researchers' ideas and research needs and the every-day circumstances of elderly people who are willing to be part of a research project? We have seen significant differences to test settings with smaller devices, such as smartphones and related applications which are nearer to the participants' every-day lives than future applications on a big TV screen, which people often doubt to be of value to them at all. Our approach to support appropriation on the basis of a stronger user- 
designer interaction was one way to foster the uptake of the technology and to foster fun and sense making in the usage (Brandt et al. 2010).

Contact: claudia.mueller@uni-siegen.de

\section{References}

Alaoui, M., \& Lewkowicz, M. (2014). Lessons Learnt from the Socio-Technical Design of Social TV Services with Elderly. International Journal of Sociotechnology and Knowledge Development, 6(2), 1-16.

Brandt, E., Binder, T., \& Malmborg, L. (2010). Communities of Everyday Practice and Situated Elderliness As an Approach to Co-design for Senior Interaction. Proc. of OZCHI 2010, 400-403.

Cesar, P., \& Geerts, D. (2011). Understanding Social TV : a survey. Proceedings of the Networked and Electronic Media Summit (NEM Summit 2011), 27.

Ducheneaut, N., Moore, R. J., Oehlberg, L., Thornton, J. D., \& Nickell, E. (2008). Social TV: Designing for Distributed, Sociable Television Viewing. IJHCI 24, 136-154.

Harboe, Gunnar and Massey, Noel and Metcalf, Crysta and Wheatley, David and Romano, G. (2007). Perceptions of value: The uses of social television. In Interactive TV: a Shared Experience.

Holt-Lunstad, J., Smith, T. B., \& Layton, J. B. (2010). Social relationships and mortality risk: A metaanalytic review. PLoS Medicine, 7(7).

Kanayama, T. (2003). Ethnographic Research on the Experience of Japanese Elderly People Online. New Media \& Society, 5(2), 267-288.

Melenhorst, A.-S., Rogers, W. A., \& Bouwhuis, D. G. (2006). Older adults' motivated choice for technological innovation: Evidence for benefit-driven selectivity. Psychology and Aging, 21, 190195.

Müller, C., Hornung, D., Hamm, T. \& Wulf, V. (2015). Practice-based Design of a Neighborhood Portal: Focusing on Elderly Tenants in a City Quarter Living Lab, Proc. of CHI'15.

Müller, C., Wan, L., Stein, M., \& Neufeldt, C. (2012). Experience of Giving and Receiving-Living Lab-based Technology Design with Elderly People. Retrieved from http://www.ischool.drexel.edu/faculty/jrode/stein.pdf

Norval. (2014). What's on your mind?: Investigating Recommendations for Inclusive Social Networking and older adults. Proc. of CHI 2014.

Palviainen, J., Kuusinen, K., \& Väänänänen-Vainio-Mattila, K. (2013). Designing for presence in social television interaction. Proc. of MUM'13, 1-10.

Plester, B., Wood, C., \& Bell, V. (2008). Txt msg n school literacy: Does texting and knowledge of text abbreviations adversely affect children's literacy attainment? Literacy, 42(3), 137-144.

Robertson, T., Durick, J., Brereton, M., Vetere, F., Howard, S., \& Nansen, B. (2012). Knowing Our Users: Scoping Interviews in Design Research with Ageing Participants. Proc. of OZCHI 2012, 517-520.

Seeman, T. E. (1996). Social ties and health: The benefits of social integration. Annals of Epidemiology, 6(5), 442-451. 